\title{
Procedure to select combined heating and hot water systems: An expeditious cost optimality approach
}

\author{
Sérgio Tadeu ${ }^{\mathrm{a}, \mathrm{b}, *}$, Márcio Gonçalves ${ }^{\mathrm{a}, \mathrm{b}}$, Nuno Simões ${ }^{\mathrm{a}, \mathrm{b}}$, Guillermo Costas ${ }^{\mathrm{c}}$, António Tadeu ${ }^{\mathrm{a}, \mathrm{b}}$ \\ ${ }^{a}$ Itecons - Institute for Research and Technological Development in Construction, Energy, Environment and Sustainability, Rua Pedro Hispano, 3030-289, Coimbra, \\ Portugal \\ ${ }^{\mathrm{b}}$ ADAI - LAETA, Department of Civil Engineering, FCTUC, University of Coimbra, Pólo II, Rua Luís Reis Santos, 3030-788, Coimbra, Portugal \\ ${ }^{\mathrm{c}}$ Industrial Engineering School, University of Vigo, Rúa Conde de Torrecedeira 86, 36208 Vigo, Spain
}

\section{A R T I C L E I N F O}

\section{Keywords:}

Cost-optimal

Energy retrofit

Buildings

Sustainability

\begin{abstract}
A B S T R A C T
The European Union has proposed a common methodology to identify energy-efficient measures with the minimum global cost throughout the lifecycle. It is known that the energy impact of a specific measure is influenced by other measures in the same package, which affect its profitability. For this reason, the cost-optimal package cannot be a simple combination of individual cost-optimal retrofitting measures. Thus, to define a cost optimal solution, the energy performance and the global cost of a large number of packages need to be calculated and analysed.

To overcome the expensive computational effort of this type of study, this work proposes an expeditious procedure for selecting the optimal energy source for heating and domestic hot water (DHW) service generation as a function of the following variables: energy needs and costs, initial investment, primary energy conversion factors and efficiency of energy systems. The method was applied to a reference dwelling in the Portuguese building stock. With the expeditious cost optimality approach, once an energy system configuration has been determined, an estimation of the cost-optimal package can be established as the sum of the most profitable options for each element.
\end{abstract}

\section{Introduction}

Buildings account for around $40 \%$ of the final energy consumption and $60 \%$ of the electricity consumption in the 28 countries of the European Union (EU). Residential buildings account for two-thirds of this consumption. Energy consumption by the building sector has increased by an average of $1 \%$ per year since 1990 [1]. As a response to this issue, policies aiming to promote energy efficiency in buildings have been adopted. The Energy Performance of Buildings Directive (EPBD) is a relevant tool that is being used to promote energy efficiency in buildings [2]. The third generation of the EPBD was published recently and Member States are expected to transpose it into national law in the next few years [3]. Two key concepts were introduced by the EPBD of 2010. One is the Nearly zero-energy building, which represents the level of efficiency that buildings should aim for. The other is the cost-optimal methodology to benchmark minimum requirements for the energy performance of buildings. This involves a balance between costs and energy savings throughout the lifecycle of a new building or in retrofitting work. The MSs were encouraged to develop national plans to promote energy efficiency in buildings following the principles of the EPBD. It is expected that energy efficiency measures could reduce the energy demand of buildings by $41 \%$ by 2050 , compared to $2005 / 06$ values [4].

The cost-optimal methodology to be followed by the MSs was published in EU Delegated Regulation 244/2012 [5,6]. It includes the establishment of reference buildings, the definition of energy-efficiency measures to be implemented in these reference buildings, the assessment of the primary energy demand of these measures, and the calculation of their cost through the net present value approach. This methodology is based on EN 15459 [7]. The cost-optimal calculation is given from both the macroeconomic and financial standpoints. The main weakness of the cost-optimal methodology is the high degree of

\footnotetext{
* Corresponding author. Itecons - Institute for Research and Technological Development in Construction, Energy, Environment and Sustainability, Rua Pedro Hispano, 3030-289, Coimbra, Portugal.

E-mail addresses: sergio.tadeu@itecons.uc.pt (S. Tadeu), marcio.goncalves@itecons.uc.pt (M. Gonçalves), nasimoes@itecons.uc.pt (N. Simões), inardesign.gbastos@uvigo.es (G. Costas), tadeu@itecons.uc.pt (A. Tadeu).

URL: http://www.itecons.uc.pt/ (S. Tadeu).
} 
flexibility when selecting the input data for the calculation: the reference building, discount rate, energy cost, energy measures, inter alia [8]. This flexibility was provided to allow the MSs to adapt their national plans to their economy, real estate market, legislation, culture, and type of climate.

Researchers have been working to address the limitations of the cost-optimal methodology, providing policy makers with useful knowledge. More specifically, the cost-optimal methodology is geared to national authorities, not to investors or users [2]. Araújo et al. [9] bridged this gap by considering the stakeholders' willingness to invest in energy-efficient solutions in retrofitting. Becchio et al. [10] included some of the benefits that the energy-efficiency elements and systems can provide in the cost-optimal calculation for a new residential building, in particular, improved indoor comfort, a higher value in the real estate market, and lower $\mathrm{CO}_{2}$ emissions. The as-built methodology considers only cash outflows.

A few measures are often chosen from a larger group of available measures at the project stage of a building renovation. Given that these measures can be combined into thousands of packages, numerical methods for determining the optimal solution are another active field of research. The Guidelines provided by the European Commission [2] mention this optimization problem but do not offer a specific methodology to solve it. In the review by De Boeck et al. [11] on studies on improving the energy performance of residential buildings, the different variables usually considered by researchers are presented, as well as methods for optimization and the sensitivity analysis. More specifically, Hamdy et al. [12] compared the performance of advanced multiobjective optimization algorithms, while the review by Tian [13] covers the sensitivity analysis methods.

Evins [14] reviewed the computational methods for optimizing sustainable building design, with the focus on residential retrofitting. This comparison showed evolutionary algorithms to be the most consistent methods. Therefore, in order to provide MSs with an advanced and robust tool, Tadeu et al. [15] used an algorithm based on the nondominated sorting genetic algorithm (NSGA)-II in the cost-optimal search in the renovation of a reference building in Portugal. Ascione et al. [16] brought together several techniques in their method to calculate the cost-optimal energy retrofit for any building: a genetic algorithm was used to search the cost-optimal packages by minimizing primary energy consumption and thermal discomfort; the procedure uses artificial neural networks to predict the building's energy performance; large-scale uncertainty and sensitivity analysis support the generation of the networks.

Of the alternative approaches, the work by Ruparathna et al. [17] is noteworthy. They used fuzzy set theory to address a weakness in the global-cost analysis of building renovation: as a data-intensive process, it is highly affected by data uncertainty and subjectivity. Fuzzy set theory helps to deal with this non-statistical uncertainty. Ruparathna et al. achieved a reliable decision criterion, which showed a considerable discrepancy in relation to traditional life-cycle costing. Eskander et al. [18] applied an improved method described by Üçtuğ et al. [19], based on linear programming, to different representative households located in the centre and north of Portugal to determine the optimal package of energy efficiency measures. Some novelties were added, notably the consideration of a new energy system, the "rebound effect" due to user behaviour once they are aware that their energy bill is lower, and the possibility to calculate the energy saved by installing better insulation and a new energy system at the same time. They focused on the financial angle, since the two clashing function objectives analysed were energy savings and investment. Lizana et al. [20] developed a methodology to determine the most effective retrofitting solutions for the residential sector. Their method enhanced decision management by discriminating the three main stakeholders: users, public administrations, and private promoters.

Given that lack of financial resources is a major barrier to building renovation, the resources that are available should be used effectively to design an optimum renovation package. Therefore, practical tools should be developed to assist decision makers. Some decision support tools have been proposed $([21,22])$, but they are time-consuming and require energy simulations using reference buildings. A great effort has been made to develop simplified tools in the form of conceptual methodologies or as software/spreadsheets. Ferreira et al. [23] analysed the decision support tools available in renovation works. Given that decision making is usually extremely time-consuming, they concluded that fast and effective methods are still needed by technicians, since only roughly $13 \%$ of the tools reviewed were considered userfriendly for technicians lacking experience in the energy performance of buildings. Bribián et al. [24] proposed to complement the EPBD with a simplified calculation method to estimate the embodied energy to support the reduction of the environmental impact.

While computationally-expensive cost-optimal problems are being tackled with the aforementioned complex techniques, the present work provides a way to make cost-optimality problems less complex. First, we describe a simplified procedure to compare the primary energy consumed by different energy systems. Second, the procedure is extended to the calculation of the energy systems with the cost-optimal approach. Then, the 'as-built' cost-optimality calculation framework provided by the European regulations is implemented to validate the selection of the energy systems and the identification of the cost-optimal package derived from the simplified method. Finally, we show the predominance of the energy system over insulating elements, enabling the cost-optimal package of fundamental measures to be estimated. The measures considered consist of using different energy systems, insulating the roof, walls or floor, and replacing windows. The proposed methodology is especially useful for planners, skilled experts, property owners, and for the systems manufacturers involved in the construction industry. This procedure can be transferred easily to a software tool used to estimate the most economically and environmentally attractive retrofitting solutions. The commonest type of Portuguese residential property was studied, as $38.1 \%$ of these buildings need urgent refurbishment works to solve indoor thermal and hygrometric comfort problems [23].

The next section presents the simplified method for comparing energy systems' configuration, firstly to assess the primary energy consumption, and secondly to evaluate their economic performance. Section 3 details the reference building and the parameters that constitute the calculation framework. The methodology is applied in Section 4: it includes the comparison with the recommended cost-optimal procedure [5] and the creation of an optimal package of measures by adding envelope improvement measures to the cost-optimal energy systems. Finally, the conclusions are presented in Section 5.

\section{Simplified procedure to evaluate the optimal configuration of the energy systems}

\subsection{Description of the problem}

In the cost-optimal methodology, the overall cost is calculated by comparing the effect that the possible energy-efficient measures would have on the energy and economic performances of a reference building, which must be defined for each project [2]. In the present study, apart from the basic economic parameters, the variables involved in the calculation were the initial investment, energy costs, primary energy conversion factors, efficiency of heating and domestic hot water (DHW) systems and useful energy needs. To relate the framework to the user's point of view, the primary energy consumption and the global cost were both calculated as a function of the useful energy needs.

The global cost-optimum is not equal to the sum of cost-optimal solutions for each of those energy measures, and this generates the optimization problem, that is, the search for the cost-optimal solution among a large number of combinations. This is because the overall cost depends on the thermal insulation characteristics, the investment, the 
operational costs and the efficiency of the energy systems, which in turn depend on how the aforementioned energy measures are combined [25]. Furthermore, some energy systems provide multiple functions heating and cooling of the living area and DHW - which increases the nonlinearity of the optimization problem. The measures included in this study are some of those most widely implemented in the energy renovation of buildings, i.e. the installation of new energy systems, the improvement roof, wall or floor insulation, and the replacement of windows. In Section 4.3, we show the predominance of energy systems over insulation when it comes to calculating the global cost for the reference building in question.

Each MS had to adapt the calculation methodology for the energy performance of buildings to its national characteristics [2]. This led to a number of simplifications to the climatic conditions, market prices and macroeconomic variables [26]. In the case of Portugal, cooling requirements can be neglected when the risk of overheating is minimal [27]. In fact, the energy used by the Portuguese residential sector for cooling was only $0.5 \%$ in 2010 [28]. This assumption was made in our study, and therefore the energy needs have been restricted to heating and DHW services.

The proposed procedure, represented in Fig. 1, allows the selection of optimum energy systems according to financial and environmental perspectives. The method uses the initial investment in each type of heating and hot-water system, the corresponding energy efficiency, the useful energy needs, and the primary energy calculated using the specific conversion factors associated with each energy source. The approach has a low computational cost and provides results similar to those obtained using the conventional cost optimal methodology defined in the delegated regulation [5]. It can also be applied to different buildings and climate regions.

\subsection{Simplified procedure: environmental criterion - primary energy consumption}

While stakeholders in building retrofitting are interested in financial profits, the motivation that has driven the European energy policy is the environmental impact associated with energy consumption. In fact, the $\mathrm{CO}_{2}$ emissions related to energy consumption are one of the main indicators mentioned in the energy performance certification of buildings. For this reason, the environmental impact of the energy systems analysed was estimated by comparing the useful energy needs that would be covered by the primary energy that they would consume. The primary energy consumption, $P E$, can be expressed in terms of the useful energy needs for heating, $E_{h}$, and for DHW, $E_{w}$ (adapted from Ref. [27]):

$P E=\sum_{k=1}^{n k}\left(\frac{f_{w, k} P_{w, k}}{\eta_{w, k}} E_{w}\right)+\sum_{j=1}^{n j}\left(\frac{f_{h, j} P_{h, j}}{\eta_{h, j}} E_{h}\right) \quad\left(k W h_{E P} /\right.$ year $)$

where $f_{w, k}$ and $f_{h, j}$ represent the share of the useful energy that is associated with each system designed for DHW and heating, respectively (with $n k$ and $n j$ being the number of DHW and heating systems); $\eta_{w, k}$ and $\eta_{h, j}$ are the efficiency of the energy systems, which convert the useful into the final energy; and $P_{w, k}$ and $P_{h, j}$ are the conversion factors from final energy to primary energy. Single DHW and heating systems

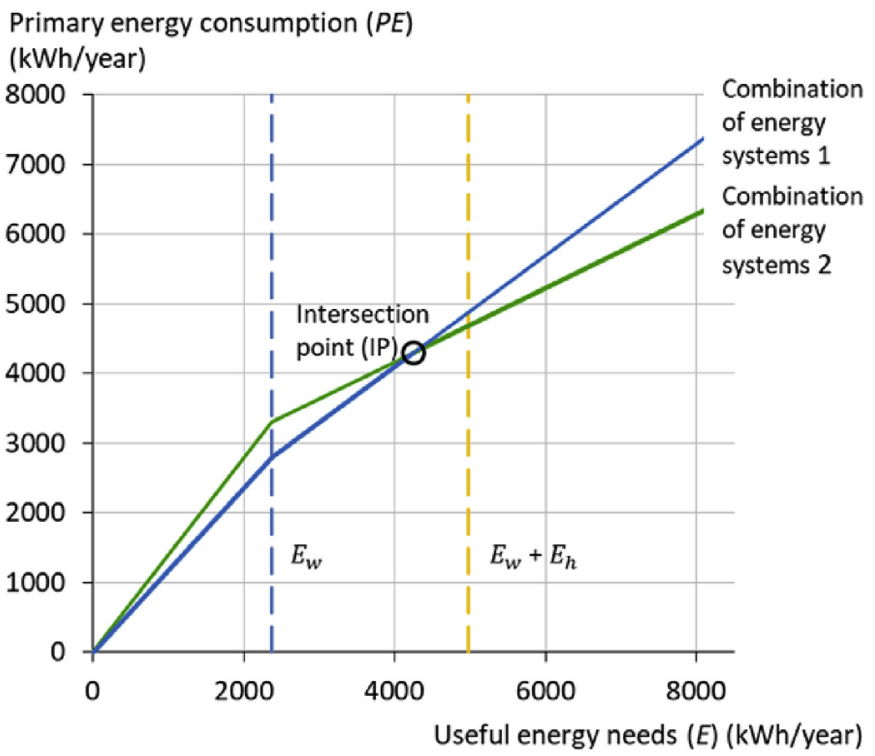

Fig. 2. Environmental evaluation of energy systems.

were considered ( $k=1$ and $j=1$ ), and $f_{w, 1}$ and $f_{h, 1}$ therefore become 1 . Thus, equation (2) is written as follows:

$P E=a_{1} E_{w}+a_{2} E_{h} \quad\left(k W h_{E P} /\right.$ year $)$

where $a_{1}=P_{w, 1} / \eta_{w, 1}$ and $a_{2}=P_{h, 1} / \eta_{h, 1}$.

If it is assumed that the first useful energy needs $(E)$ are only associated with DHW, the previous equation becomes:

$P E=a_{1} E \quad\left(k W h_{E P} /\right.$ year $)$

Then, if we assume that after the total DHW needs $\left(E_{w}\right)$ are satisfied the increase in useful energy needs is only associated with heating, the following equation is obtained:

$P E=\left(a_{1}-a_{2}\right) E_{w}+a_{2} E \quad\left(k W h_{E P} /\right.$ year $)$

Fig. 2 illustrates how this relationship between primary energy needs and useful energy consumption can be used to compare the efficiency of each set of DHW and heating systems (hypothetical energy system sets 1 and 2). The solution of the most efficient set of energy systems can be easily identified as a function of the DHW $\left(E_{w}\right)$ and the heating $\left(E_{h}\right)$ needs.

For the given energy needs indicated $\left(E_{w}+E_{h}\right)$, energy system set 2 would be more energy efficient than set 1 . However, energy system 1 would be the optimal choice if the energy needs fell below the useful energy need for which both systems have the same primary energy consumption, the intersection point (IP). The polygonal curve formed by the segments of the linear equations with the greatest efficiency, crossing at intersection points, identifies the most efficient energy system for each useful energy need. In the example given, both energy system sets use separate DHW and heating systems. If a single energy system provides both services, the associated graphic would become a straight line if its efficiency at producing DHW were the same as for heating.

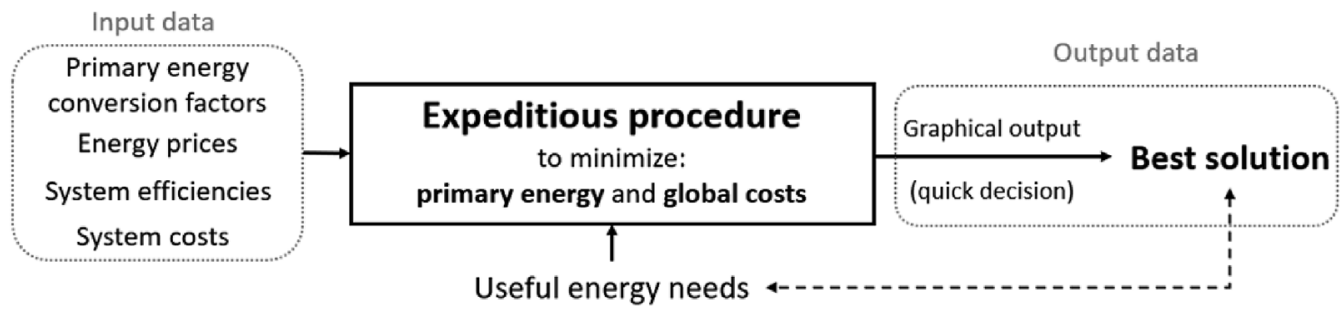

Fig. 1. Scheme of the proposed expeditious procedure. 


\subsection{Simplified procedure: economic criterion - global cost}

The cost-optimal procedure established by the European Commission favours expressing the global cost as a function of the primary energy consumed by the building. The simplified procedure presented in this section is based on useful energy needs. The costs taken into account and the economic parameters, such as the expected useful life of energy systems, were those established by EN 15459 [7] and provided for by the Delegated Regulation 244/2012 [5]. The starting point is the following formula for the total cost $G C$ of a set number of measures $N M$, calculated from the financial perspective as a net present value over the period $\tau$ years:

$G C=\sum_{j=1}^{N M}\left[I_{j}+\sum_{i=1}^{\tau}\left(C_{j, i} \cdot D_{i}\right)-\left(V_{\tau, j} \cdot D_{\tau}\right)\right]$

in which $j$ is the measure (energy system set) being analysed; $I_{j}$ is the investment costs; $C_{j, i}$ represents the annual cost, which is subject to the discount factor $D_{\tau} ; V_{\tau, j}$ is the residual value associated with each measure, calculated at the end of the period by applying the discount factor $D_{\tau}$. The discount factor for year $i D_{\tau}$, is calculated by the following formula:

$D_{\tau}=\left(\frac{1}{1+r / 100}\right)^{i}$

where $r$ is the real discount rate (\%).

The cost-optimal methodology described in Refs. [5,6] suggests a general period of $\tau=30$ years for the calculation. However, a life cycle of 20 years was considered in this study since EN 15459 establishes this is the life span assumed for most of the energy systems under study. This avoids having to deal with replacement costs and residual values. From the financial perspective, value-added tax (VAT) and other applicable taxes are included. The investment amount considered depends on the energy system, and the annual cost includes maintenance and energy costs.

Next, the global cost is calculated for the energy measure that consists of installing a new energy system or a set of them. The first indicator to be analysed is the total cost associated with the useful energy needs of a DHW system. Taking into account the aforementioned assumptions, the global cost for the DHW system $w, k$ can be expressed as follows:

$G C_{w, k}=I_{w, k}+\sum_{i=1}^{\tau}\left(M_{w, k, i}+E C_{w, k, i}\right) D_{r}$

where $M_{w, k, i}$ is the maintenance cost in the year $i, E C_{w, k, i}$ is the energy costs in the year $i$, which depend on the annual final energy use $F E_{\mathrm{w}, k}$ and the energy price $C_{e n, w, k, i}$ :

$E C_{w, k, i}=F E_{w, k} C_{e n, w, k, i}$

The final energy needs have to be converted into useful energy $E_{w}$ as in the previous section:

$F E_{w, k}=\frac{f_{w, k}}{\eta_{w, k}} E_{w} \quad\left[\mathrm{kWh} /\left(\mathrm{m}^{2}\right.\right.$. year $\left.)\right]$

And if DHW is again provided by a single system $(k=1)$, equation (7) becomes:

$G C_{w, 1}=I_{w, 1}+\sum_{i=1}^{\tau}\left(M_{w, 1, i}+C_{e n, w, 1, i} \frac{1}{\eta_{w, 1}} E_{w}\right) D_{r}$

Thus, the total cost turns into a linear function of the useful energy needs $E_{w}$ :

$G C_{w, 1}=\mathrm{b}_{1}+\mathrm{b}_{2} E_{w} \quad €$

where $\mathrm{b}_{1}=I_{w, 1}+\sum_{i=1}^{\tau} M_{w, 1, i} D_{r}$ and $\mathrm{b}_{2}=\sum_{i=1}^{\tau}\left(C_{e n, w, 1, i} \frac{1}{\eta_{w, 1}} D_{r}\right)$.
Similarly, the total cost for a heating system can be expressed as:

$G C_{h, 1}=\mathrm{c}_{1}+\mathrm{c}_{2} E_{h}$

where $\mathrm{c}_{1}=I_{h, 1}+\sum_{i=1}^{\tau} M_{h, 1, i} D_{r}$ and $\mathrm{c}_{2}=\sum_{i=1}^{\tau}\left(C_{e n, h, 1, i} \frac{1}{\eta_{h, 1}} D_{r}\right)$.

Replacing both energy systems, combining equations (11) and (12) leads to:

$G C=\mathrm{b}_{1}+\mathrm{c}_{1}+\mathrm{b}_{2} E_{w}+\mathrm{c}_{2} E_{h}$

As before, if it is assumed that the useful energy needs $(E)$ are at first only associated with DHW, this equation becomes:

$G C=\left(b_{1}+c_{1}\right)+b_{2} E$

In this equation it is assumed that the initial investment and maintenance costs are related to both systems, as they are accountable, even if not used. Then, once DHW needs are covered, they remain constant and subsequent increases in useful energy needs are assigned to heating. This leads to the following equation:

$G C=\left(b_{1}+c_{1}+\left(b_{2}-c_{2}\right) E_{w}\right)+c_{2} E \quad(€)$

It is observed that the energy system used for heating affects the global cost, even when only DHW is consuming energy. Equations (14) and (15) and their use are illustrated in Fig. 3. In this hypothetical example, energy system 2 turns out to be more economically attractive for the energy needs specified in the retrofitting project. In conclusion, energy system 2 would be the most environmentally and economically attractive energy system in the range of useful energy demand defined by the intersection points of Figs. 2 and 3. With the DHW needs kept constant, modifying the heating demand shown in both Figures would improve one of the objective functions at the cost of worsening the other one.

\section{Case study}

\subsection{Definition of the reference building}

With a share of roughly $44 \%$, residential buildings constructed between 1960 and 1990 constitute the majority of the Portuguese building stock [29]. Since the first Portuguese energy performance regulation dates from 1990, houses built up to then did not follow any particular requirements regarding energy efficiency. Most were built of masonry with single glazed windows using a cold aluminium frame (without a thermal break), while the roofs were generally sloping with

Global cost (GC)

(€)

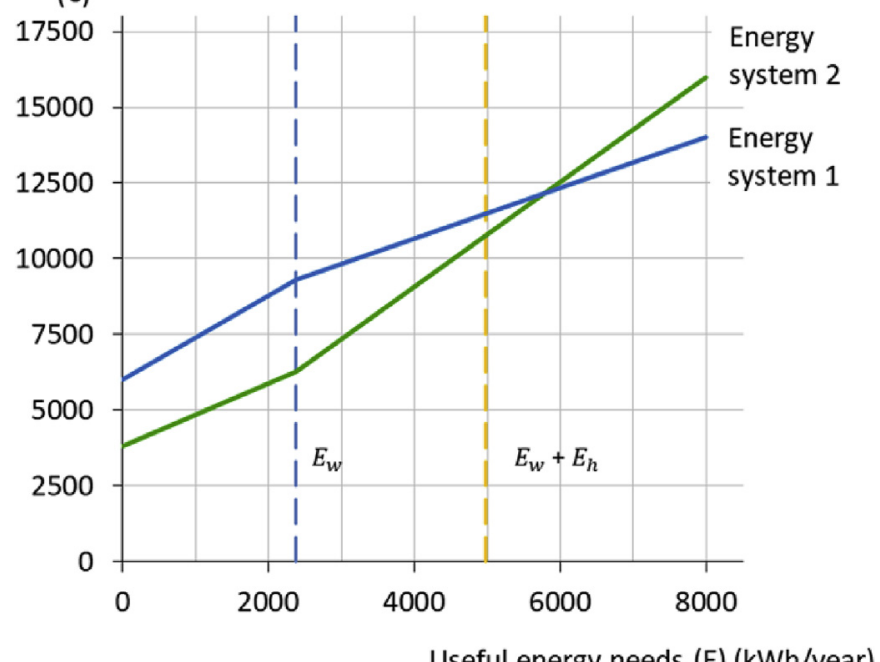

Fig. 3. Economic evaluation of energy systems. 


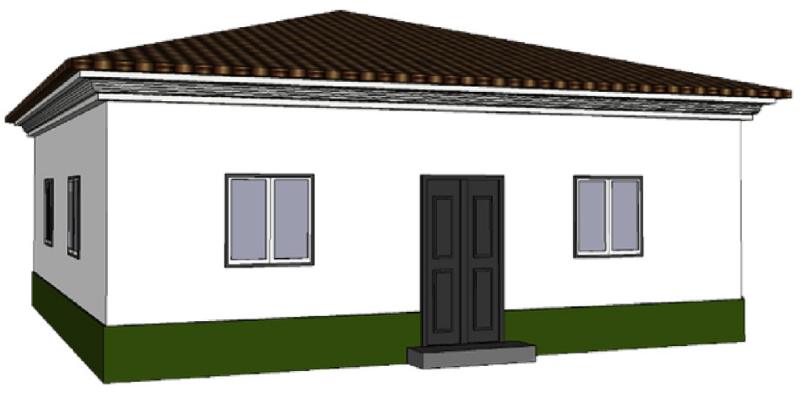

Fig. 4. Reference building.

ceramic tiles laid on a wooden structure, without insulation [30]. To validate the simplified method described, a reference building was defined that would represent the detached houses built in that period. Its geometric and thermal characteristics were established based on two sources. One is the database Energy Certification System (ECS) [31], provided by the National Agency for Energy (ADENE). It contains statistical data from more than one million certificates. The other is the statistical data provided by the National Statistics Institute (INE) and the General Directorate for Energy and Geology (DGEG) [28]. From these data it was concluded that a typical model consists of a single storey 3-bedroom house with masonry walls (see Fig. 4). Rooms would be heated by electric heaters, whose nominal efficiency is $100 \%$, while a gas heater with an average efficiency of $60 \%$ would be used for DHW [32].

Walls would be made of masonry. The internal dimensions of the reference building and its thermal characteristics are indicated in Table 1 . The glazed area was assumed to be distributed equally between the four directions of the façades (north, south, east and west) and the solar factor $g_{w}$ included in Table 1 is an averaged value. Shading devices were assumed to be light coloured curtains made of a thin fabric that would have an obstruction factor of 0.38 . It was also found that the thermal inertia corresponds to an intermediate class of the energy storage capacity $[27,33]$.

This study focuses on dwellings built between 1960 and 1990 . However, both for those built before 1960 [34] and for historic buildings [35], replacing low-efficiency energy systems with high-efficiency ones is substantially more cost effective than improving the envelope insulation. Actually, investing in high-efficiency equipment even reduces the need to improve the insulation of the façades, which is usually one of the most expensive measures [36].

\subsection{Climate data}

Portugal is a country in south-western Europe and has a predominantly Mediterranean climate, with the Köppen classification of Csa/Csb (warm temperate, dry summer, and hot-mild summer) [37]. With regard to the heating needed in the cold season, the national regulation divides the country into three climate zones (I1, I2 and I3),

Table 1

Dimensions and thermal characteristics of the reference building.

$\begin{array}{ll}\text { Living space floor area } A_{u}\left(m^{2}\right) & 100 \\ \text { Height of ceilings } h_{m}(\mathrm{~m}) & 2.70 \\ \text { Envelope area } A_{e}\left(\mathrm{~m}^{2}\right) & 93 \\ \text { Windows area } A_{W}\left(\mathrm{~m}^{2}\right) & 15 \\ \text { Roof area } A_{r}\left(\mathrm{~m}^{2}\right) & 100 \\ \text { Thermal transmittance of walls } U_{e}\left(\mathrm{~W} / \mathrm{m}^{2} \mathrm{~K}\right) & 1.76 \\ \text { Thermal transmittance of floor } U_{f}\left(\mathrm{~W} / \mathrm{m}^{2} \mathrm{~K}\right) & 1.65 \\ \text { Thermal transmittance of roof } U_{r}\left(\mathrm{~W} / \mathrm{m}^{2} \mathrm{~K}\right) & 2.80 \\ \text { Thermal transmittance of windows } U_{w}\left(\mathrm{~W} / \mathrm{m}^{2} \mathrm{~K}\right) & 5.10 \\ \text { Obstruction factor of windows } & 0.38 \\ \text { Windows solar gain heat coefficient } g_{w} & 0.85 \\ \text { Air renewal rate }\left(h^{-1}\right) & 0.4\end{array}$

which are used to set the envelope's thermal requirements. The heating degree days and duration of the heating season (HDD) depend on the building's location and altitude. The range of degree days for mainland Portugal varies from $987^{\circ} \mathrm{C}$.day HDD to $2015^{\circ} \mathrm{C}$.day HDD [27], which influences the calculation of the cost optimal levels in Portugal [38]. Coimbra, the location assigned to the reference building, lies in climate zone (I2, V2) and has a $1304^{\circ} \mathrm{C}$.day HDD.

\subsection{Energy needs of the reference scenario}

The energy needs considered in this study were for heating and to produce DHW. The actual heating usage habits of users depends on a number of variables such as weather, dwelling morphology, envelope insulation, occupant profile (age, renter/owner, household size, energy use awareness, etc.), time of day, energy price, and others [39]. National regulations and energy performance certification frameworks make a number of simplifications to drastically reduce the variables involved in calculating energy needs. For example, a survey conducted in 2012 on 8500 retrofitted Greek dwellings found that the average energy consumption was $44 \%$ lower than the calculated value [40]. The energy performance data for 3400 German homes indicates that the measured energy consumption for DHW and heating is on average $30 \%$ lower than that calculated [41]. In the case of mainland Portugal, Magalhães et al. [42] concluded that the heating energy needs are only $5 \%$ of the calculated needs indicated in the energy performance certifications. They included 259,775 certificates in the analysis, and the actual energy consumption was calculated from the national energy balance using a top-down approach.

The Portuguese regulation uses the seasonal method [27] described in EN ISO 13790 [43] to estimate the energy needs for residential units. One of the most relevant simplifications is the assumption of the permanent use of equipment for thermal comfort. However, when the habits of the occupants are taken into account, the value of the energy needs decreases markedly (as a rule, people do not heat all the building space all the time). To carry out a realistic calculation in the present work, a reduction factor was applied to the nominal (according to the Portuguese regulation) energy needs for heating. This factor was determined using data from the Portuguese energy performance certification system, (Sistema Nacional de Certificação Energética dos Edifícios, SCE) [44] and from a Portuguese survey, Inquérito ao Consumo de Energia no Sector Doméstico (ICESD) [28]. The database of the SCE was the source of the energy consumption figures according to the building regulation $([27,31])$, while information from the ICESD enabled the assessment of the final values of the energy actually consumed in buildings for various uses, including heating, cooling and domestic hot water. According to the $S C E$, the annual useful energy consumption for heating per dwelling is $117.7 \mathrm{kWh} / \mathrm{m}^{2}$ and the average efficiency of heating systems is 1.91 , resulting in an annual final energy consumption of $61.6 \mathrm{kWh} / \mathrm{m}^{2}$. According to the ICESD, $51.7 \%$ of households use electricity for heating, and the annual electricity consumption for heating an average area of $50.6 \mathrm{~m}^{2}$ was $418.6 \mathrm{kWh}$. This is $13.4 \%$ of the figure reported by $S C E$. This percentage was adopted in this work as a reduction factor for the useful energy needs for heating estimated by the seasonal method [36].

The reduction factor was afterwards used in the energy calculation method adapted from Ref. [45]:

$E_{h}=Q_{t r}+Q_{v e}-Q_{\text {gain }} \quad(\mathrm{kWh} /$ year $)$

where,

- $Q_{t r}$ is the transmission heat transfer coefficient (expressed in $\mathrm{kWh}$ ), obtained by multiplying the total annual heating degree-hours (HDD x 24) by the overall coefficient of heat transfer by transmission;

- $Q_{v e}$ is the heat transfer coefficient by ventilation (expressed in $\mathrm{kWh}$ ), obtained by multiplying the total annual heating degree-hours (HDD $x 24$ ) by the overall coefficient of heat transfer by ventilation; 
- $Q_{\text {gain }}$ is the net heat gain (expressed in $\mathrm{kWh}$ ), obtained by multiplying the average internal gains of the total surface by the average duration of the conventional heating season and by the internal floor area.

The nominal needs of useful energy for DHW indicated by the Portuguese regulation [27] are calculated using the following formula:

$E_{w}=\frac{M 4187 \Delta T n_{d}}{3600000} \quad(\mathrm{kWh} /$ year $)$

where $\Delta T$ is the temperature gap necessary for DHW supplies and the value of $35^{\circ} \mathrm{C}$ was established; $n_{d}$ is the annual number of days energy is consumed, taken to be 365 days; and $M$ is the average daily DHW consumption, which depends on the usual number of occupants, $n_{0}$, and on the hydric efficiency factor, $f_{e h}$, for which the conventional value of 1 was assumed. In this reference scenario, four persons were considered to be living in the dwelling.

$M=40 \quad n_{o} f_{\text {eh }}$ litres/year

For the scenario considered, $M$ results in 160 litres/day and $E_{w} 2377.3 \mathrm{kWh} /$ year. This value is quite close to real consumption at national level [28] and therefore no adjusting factor was applied.

\subsection{Definition of the energy systems considered}

The characteristics of combined heating and DHW systems proposed in this study are listed in Table 2. Investment costs are shown in Table 3. To perform the economic evaluation of DHW and heating separately when the system provides both services (sets 3 and 4), the investment in energy system equipment was assumed to be proportional to the DHW and heating energy needs $\left(E_{D H W}\right.$ and $\left.E_{h}\right)$.

\subsection{Financial data}

A cost optimality study depends on the price trend of energy and, to a lesser extent, on $\mathrm{CO}_{2}$ emission costs. The EU has published the energy price trends until 2050 [46] and the prices of $\mathrm{CO}_{2}$ were set by the European Union Emissions Trading Scheme (EU ETS). Initial energy costs were obtained from Portugal's Energy Regulator, ERSE [47]: $€ 0.23 / \mathrm{kWh}$ for electricity and $€ 0.077 / \mathrm{kWh}$ for natural gas. The discount rate, which is adjusted according to the degree of risk relative to estimated cash flows, is generally higher for riskier assets. We have assumed $5 \%$ for the financial perspective. This is the current rate in Portugal for loans for rehabilitation projects for rental purposes [48].

\subsection{Investment and operational costs}

An economic evaluation of the solutions most often used in Portugal was performed for the insulation materials and heating and DHW systems. Investment costs associated with these systems were based on current market figures [49]. For replacement costs, a lifespan of 50 years was assumed for insulation, 40 years for windows and 20 years for mechanical systems. In our analysis, the maintenance costs were

Table 2

Characteristics of the configuration of each energy system set.

\begin{tabular}{|c|c|c|c|c|c|c|}
\hline & DHW system & $P_{w, 1}^{a}$ & $\eta_{w, 1}$ & Heating system & $P_{h, 1}^{a}$ & $\eta_{h, 1}$ \\
\hline Set 1 & $\begin{array}{l}\text { Gas water heater } \\
(\mathrm{GWH})\end{array}$ & 1.0 & 0.60 & Electric heater (EE) & 2.5 & 1.00 \\
\hline Set 2 & $\begin{array}{l}\text { Gas water heater } \\
(\mathrm{GWH})\end{array}$ & 1.0 & 0.78 & Heat pump (HP) & 2.5 & 4.30 \\
\hline Set 3 & Gas boiler (GB) & 1.0 & 0.83 & Gas boiler (GB) & 1.0 & 0.93 \\
\hline Set 4 & Biomass boiler (BB) & 1.0 & 0.92 & $\begin{array}{l}\text { Biomass boiler } \\
\text { (BB) }\end{array}$ & 1.0 & 0.92 \\
\hline
\end{tabular}

${ }^{\text {a }}$ Conversion factor to primary energy needs [27] in $\mathrm{kWh}_{\mathrm{EP}} / \mathrm{kWh}$. assumed to be $1 \%$ of the initial investment, in accordance with the predominant values indicated in EN 15459 [7]. Running costs depend on the correlation between energy consumption, energy prices and system efficiency.

\section{Results and discussion}

\subsection{Application of the expeditious procedures to the reference building}

\subsubsection{Primary energy consumption}

Following the calculation explained in Section 2, a dwelling occupied by four persons, would accounts for needs of DHW $E_{w}=2377$ $\mathrm{kWh} /$ year. The results for the four energy systems' configurations are shown in Fig. 5. When the useful energy covered is assigned only to DHW, the higher efficiency of GWH combined with HP (GWH, $\left.\eta_{w, k}=0.78\right)$ is essential to achieve a better performance than the older GWH $\left(\eta_{w, k}=0.60\right)$ combined with EE. In Fig. 5, we can see that for the simulation scenario, where useful energy needs for heating and for DHW are $4981 \mathrm{kWh}$ /year, GWH + HP will have lower primary energy needs or less environmental impact, according to this criterion. Note also that BB is always better than GB in terms of the efficient use of primary energy.

From the project engineer's point of view, it is interesting to identify the point where both systems have the same useful and primary energy need, since from this intersection point, we can choose the systems considering their environmental impact (expressed by $P E$ ). The configurations $\mathrm{GWH}+\mathrm{HP}$, and $\mathrm{GB}$, intersect at the point ( $E=2746 \mathrm{kWh} /$ year, $P E=3272 \mathrm{kWh}$ PE $/$ year). If the useful energy needs increase to more than $2746 \mathrm{kWh}$ /year, the GWH + HP solution begins to show a lower environmental impact than GB. This would be the case if no reduction factor were applied to the heating energy needs calculated with the seasonal method $(19,432 \mathrm{kWh} /$ year $)$.

\subsubsection{Global cost - DHW system}

Next, the economic evaluation of the energy systems is analysed through their global cost. The result of the different energy system configurations is shown in Fig. 6. The linear equation for each energy system (equation (11)) is obtained by using in equation (10) the economic parameters given in Section 3: investment, maintenance cost as a function of investment, the period of calculation, the prices of the different types of energy, and the efficiency of the systems.

For each useful energy need, the cost-optimal system is identified by the segments that minimize the global cost before and after the intersection point $I P$ (at $E=441.8 \mathrm{kWh} /$ year). It can be seen that for the reference occupancy of four users the efficiency and initial cost of a GWH would be critical to it becoming the least or the most cost-efficient solution. Even if only one user were living in the dwelling, the highly efficient GWH would be the cost-optimal solution, since in that case $E_{w}=594.3 \mathrm{kWh} /$ year , which exceeds the useful energy need corresponding to the $I P$. If there is a change in the occupancy profile, then the cost-efficient energy system would change only if the updated DHW needs changed until they passed the useful energy needs of any intersection point.

\subsubsection{Global cost - heating system}

When the heating system is analysed alone, the global cost is calculated through the same parameters used in the previous section, but through equation (12). The results can be compared in Fig. 7. GB is the most cost-efficient system for a broad range of deviation from the heating demand calculated for the reference scenario. Even though HP and $\mathrm{BB}$ are more energy-efficient, the high investment they require removes their economic attractiveness.

The large gap between real energy consumption (reference scenario: $E_{h}=2604 \mathrm{kWh} /$ year) and estimated energy consumption according the Portuguese regulation (seasonal method: $E_{w}=19433 \mathrm{kWh} /$ year, can have a very negative economic impact on the promoter of the 
Table 3

Investment and energy costs (VAT and taxes included) for the configuration of each energy system.

\begin{tabular}{|c|c|c|c|c|c|c|}
\hline & DHW system & Investment $I_{w, 1}(€)$ & Energy cost $C_{e n, w, 1, i}(€ / \mathrm{kWh})$ & Heating system & Investment $I_{h, 1}(€)$ & Energy cost $C_{e n, h, 1, i}(€ / \mathrm{kWh})$ \\
\hline Set 1 & GWH & 457.7 & 0.1032 & $\mathrm{EE}$ & 1189.8 & 0.230 \\
\hline Set 2 & GWH & 534.7 & 0.1032 & HP & 6034.1 & 0.230 \\
\hline Set 3 & $\mathrm{~GB}^{\mathrm{a}}$ & 1058.5 & 0.1032 & $\mathrm{~GB}^{\mathrm{a}}$ & 1101.8 & 0.077 \\
\hline Set 4 & $\mathrm{BB}^{\mathrm{a}}$ & 3819.0 & 0.0492 & $\mathrm{BB}^{\mathrm{a}}$ & 4010.0 & 0.045 \\
\hline
\end{tabular}

a The investment cost was shared between heating (51\%) and DHW (49\%), as set in the baseline scenario (2377 over $4832 \mathrm{kWh} / \mathrm{year}$ ). The share was modified appropriately for the other scenarios.

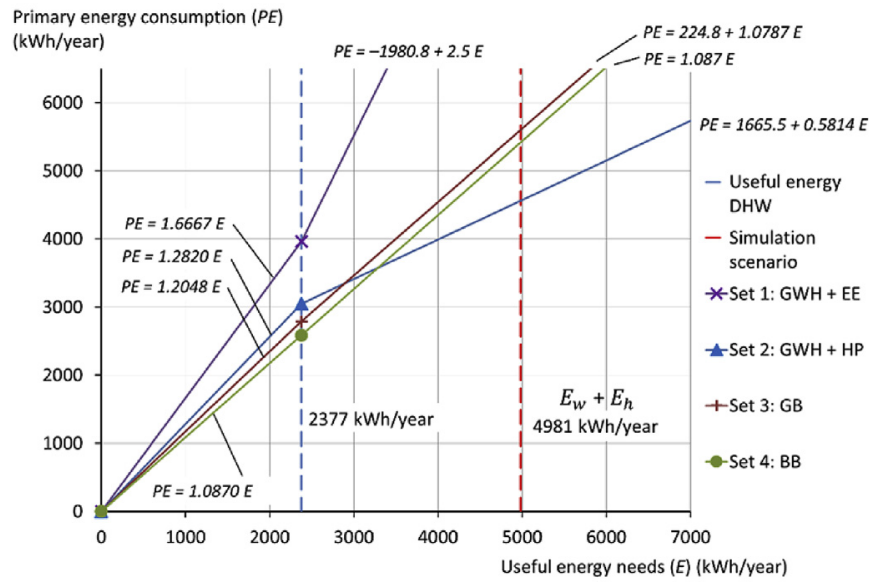

Fig. 5. Relation between primary energy consumption and useful energy needs for different energy systems.

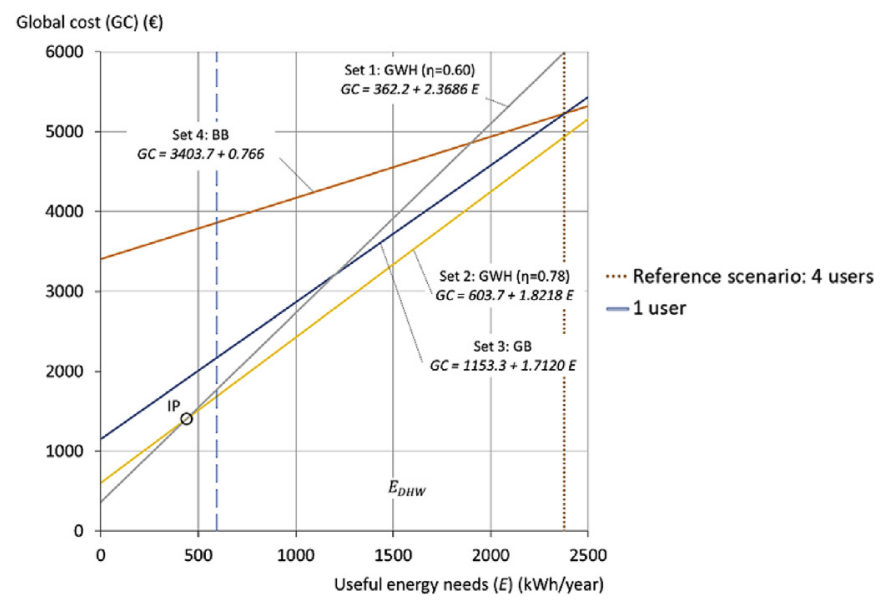

Fig. 6. Economic evaluation of energy systems used for DHW and with no heating retrofitting.

renovation. If the seasonal method were followed, then the optimal energy system would be BB. This system has a greater investment than GB and, moreover, the energy savings over the years would be lower than expected, so that the real total cost of BB would be overestimated.

\subsubsection{Global cost - DHW and heating systems}

The global costs calculated for the reference scenario in the general case, when both DHW and heating services are required, are detailed in Table 4. These linear equations correspond to equations (14) and (15). The useful energy needs of the scenario are $4981.0 \mathrm{kWh} /$ year, which includes DHW and heating. It is concluded that when the heating service begins to consume energy GB is the most cost-effective solution until $E=6969.2 \mathrm{kWh} /$ year (IP 1), with heating accounting for $4592.2 \mathrm{kWh} /$ year. Above this value, the biomass boiler would have the lowest global cost of the other alternatives. GB would be still the

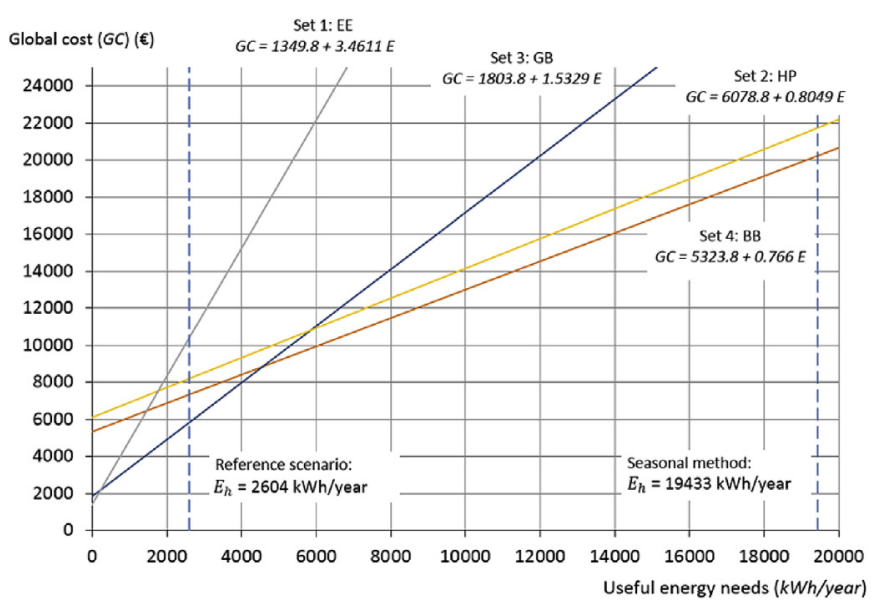

Fig. 7. Economic evaluation of energy systems used for heating, and with no DHW retrofitting.

Table 4

Linear equations of global cost $(G C)$ in $€$ for the energy systems considered.

\begin{tabular}{|c|c|c|}
\hline & $0 \leq E \leq E_{D H W}$ & $E>E_{D H W}$ \\
\hline Set 1 & & $G C=-885.7+3.4611 E$ \\
\hline Set 2 & & $G C=9099.5+0.8049 E$ \\
\hline Set 3 & & $G C=3382.9+1.5323 E$ \\
\hline Set 4 & & \\
\hline
\end{tabular}

optimal solution if only DHW were demanded, since the useful energy needs corresponding to IP 2 are lower than DHW needs.

\subsection{Validation in the EU's cost-optimal methodology}

To validate the procedure applied in the previous section, the calculation was carried out following the 'as-built' methodology described in Delegated Regulation (EU) 244/2012 [5]. This analysis included the energy systems from Tables 2 and 3 and six different insulation thicknesses for the roof, exterior walls and ground floor. The results, presented in Fig. 9, are compared with those obtained with the expeditious procedure. The Portuguese regulation on energy performance certification establishes an upper limit for the primary energy consumed for each energy technology [27]. As can be seen in Fig. 9, these limits (coloured vertical lines) make it possible to discard a substantial number of packages of energy measures.

The economic analysis carried out in the previous section indicated that GB is the most cost-effective option for the energy needs studied, followed by $\mathrm{BB}$. The results of the official methodology (shown in Fig. 9) confirm that GB and BB generate the curves with the most costefficient packages of measures. Consequently, the simplified procedure would discard the other two solutions for energy systems in the simulation of the cost-optimal solutions, thereby substantially reducing the number of combinations in a 'full-scale' cost-optimal analysis. More precisely, the cost-optimal package provided by the official cost- 


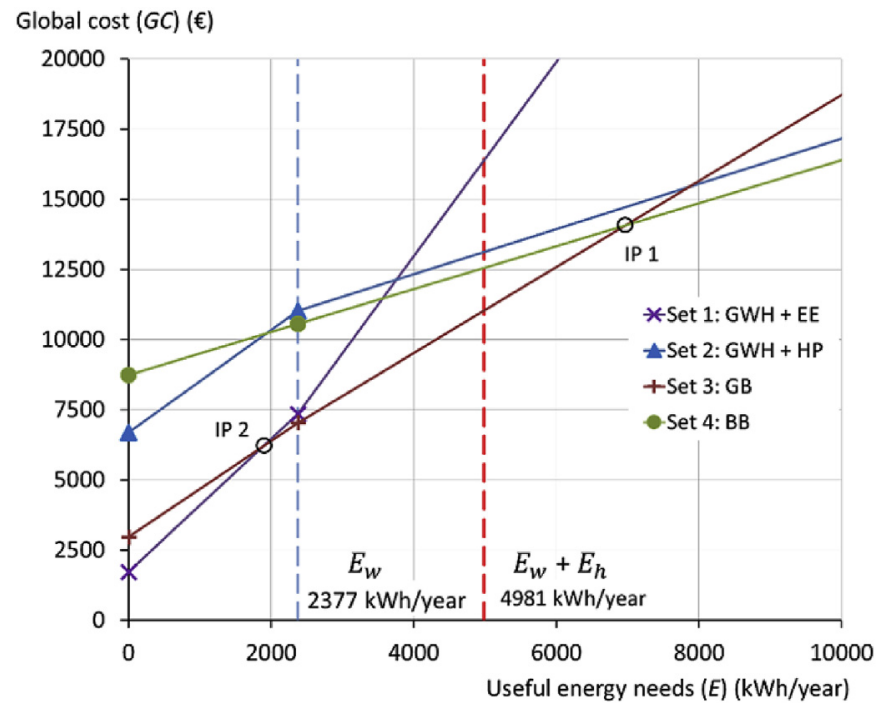

Fig. 8. Global cost of retrofitting energy systems.

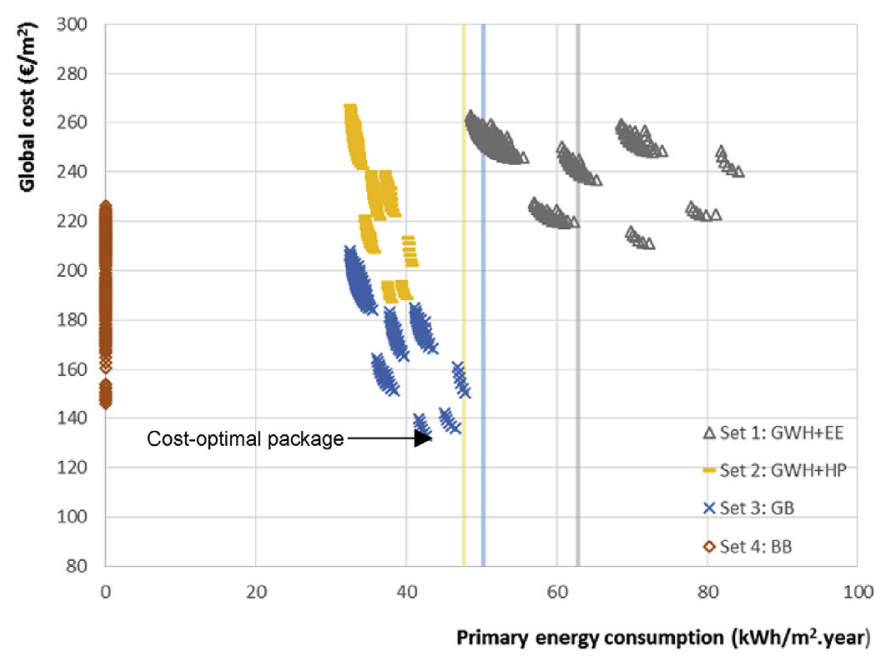

Fig. 9. Global cost of all the combinations of energy efficiency measures, grouped by heating and DHW systems - reference building.

optimal methodology consists of the GB set combined with roof insulation consisting of expanded polystyrene, $60 \mathrm{~mm}$ thick.

To compare and validate the application of the expeditious procedure proposed in this paper, other calculations based on the European methodology framework were performed. So, Fig. 9 presents the results for a reference building of 150 square metres and with 4 occupants. Fig. 10 presents the results for a reference building of 200 square metres with 7 occupants.

The results of the official methodology shown in Fig. 10 confirm that GB has the most cost-efficient packages of measures. In this case, the total useful energy need is $5478.0 \mathrm{kWh} /$ year. This energy consumption is lower than the IP 1 , so it was expected that the cost-optimal solution would have GB. According to Fig. 8, it is expected that the BB packages of measures would become the most cost-efficient for energy consumption higher than $6969.2 \mathrm{kWh} /$ year (IP 1). This is demonstrated in Fig. 10. Comparing Fig. 9 with Fig. 10, we can see that the GWH + HP optimal-cost curve gets close to the GB optimal cost-curve. This result shows the approximation between set 2 and set 3 curves, as useful energy needs increase, shown in Fig. 8.

The results of the official methodology shown in Fig. 11 confirm that BB has the most cost-efficient packages of measures. In this case, the total useful energy need is $7794.7 \mathrm{kWh} /$ year. This energy

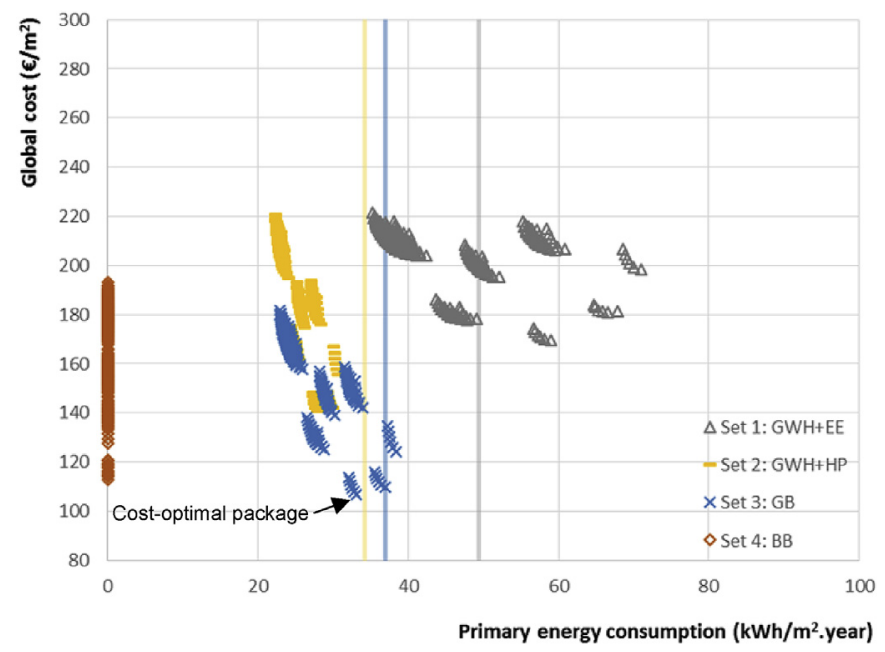

Fig. 10. Global cost of all the combinations of energy efficiency measures, grouped by heating and DHW systems - reference building of $150 \mathrm{~m}^{2}$ with 4 occupants.

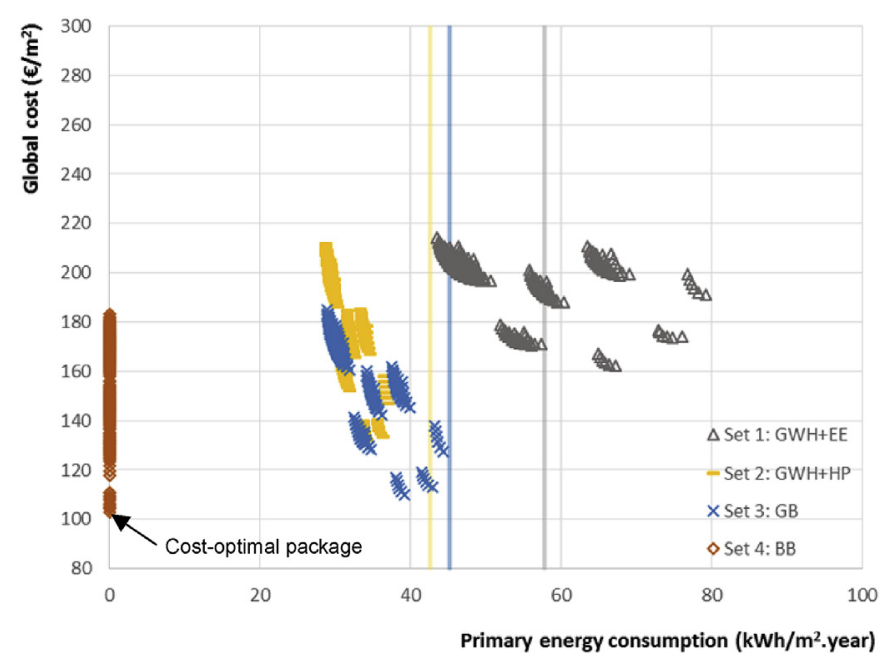

Fig. 11. Global cost of all the combinations of energy efficiency measures, grouped by heating and DHW systems - reference building of $200 \mathrm{~m}^{2}$ with 7 occupants.

consumption is higher than the IP 1 , so it was expected that the costoptimal solution would be with $\mathrm{BB}$, according de expeditious procedure. Thus, we can conclude that the proposed expeditious procedure to support the selection of combined heating and DHW systems provides the same results as the recommended cost-optimal method established by EU regulations. This expeditious procedure avoids the high computational demand required when a large number of packages of energy efficiency measures are necessary.

\subsection{Building up the package of measures from the simplified procedure}

Next, it is shown that when a set of available heating systems are combined with insulation measures, the choice of energy system has a stronger impact on the global cost analysis than the impact of the insulation improvements. This predominance of the heating systems means that the cost-optimal package of energy measures can be estimated as the sum of each cost-optimal measure separately: first, the energy system configuration for DHW and heating is chosen using the simplified procedure described in Section 2; then, the elements to be insulated are identified, since they are closely related to the energy systems chosen, as shown below; and finally the viability of upgrading 


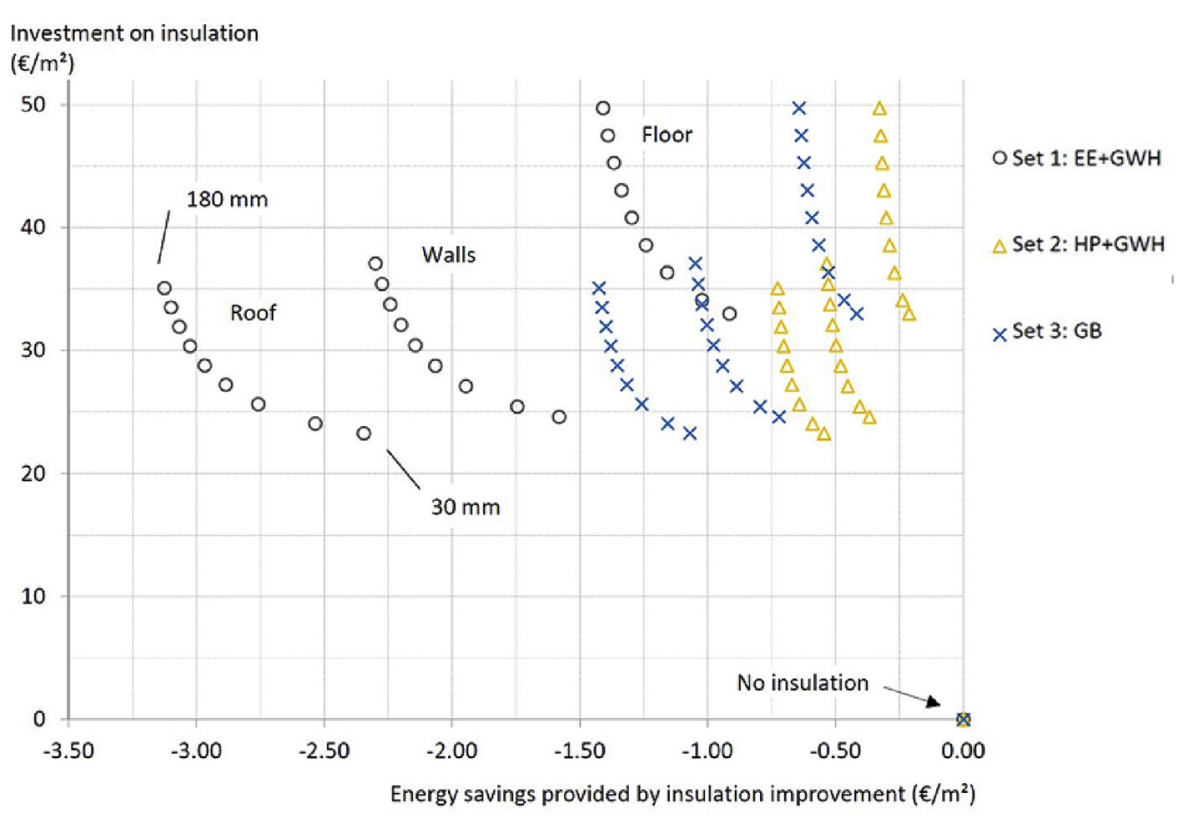

Fig. 12. Reduction in heating energy bill for different systems due to improving thermal insulation.

the windows of the building is assessed.

First, the relation between energy savings $\left(€ / \mathrm{m}^{2}\right)$ and the investment in insulation is shown in Fig. 12. Each points curve is generated by changing the thickness of insulation: $30 \mathrm{~mm}, 40 \mathrm{~mm}$, and then increasing in increments of $20 \mathrm{~mm}$ up to $180 \mathrm{~mm}$. The investment increases as the thickness increases. The EE system consumes much more energy and therefore has greater potential for energy savings through improving insulation or by switching to another energy system. In fact, certain energy savings would be achieved by switching to GB or HP, even without improving the insulation. It can be seen that, keeping all other parameters unchanged, the choice of energy system affects the energy savings more than the choice of the element to be insulated and the insulation thickness.

Second, the impact on the global cost, on the reduction of useful energy needs for heating with the energy systems, and on the insulation and windows chosen, is shown in Fig. 13. The global cost was calculated following the official methodology [5]. For each energy system, the changing parameters were the type and thickness of insulation, and the characteristics of any new windows to be installed. Thus, the difference which appears on the horizontal axis $[x]$ occurs only by increasing insulation, since each window is compared with itself in a scenario where there is no insulation and the system is the same. The influence of windows on energy savings is negligible, and therefore they essentially increase the global cost. Thus, as can be seen on the vertical axis $[y]$ for $x=0$, the window that provides the lowest global cost is always already in the reference building $\left(U_{w}=5.10\left[\mathrm{~W} /\left(\mathrm{m}^{2} .{ }^{\circ} \mathrm{C}\right)\right]\right)$, regardless of the system. This relationship does not change when the insulation costs are added. Apart from the fact that the window area is only $15 \%$ of the envelope area, the solar factor of more advanced windows is lower than the default one. This supports the performance of the building when cooling is needed, which is often not necessary in Portuguese dwellings, as noted earlier. A lower solar factor, however keeping the same heat transfer coefficient $U$ - increases the heating needs in the cold season.

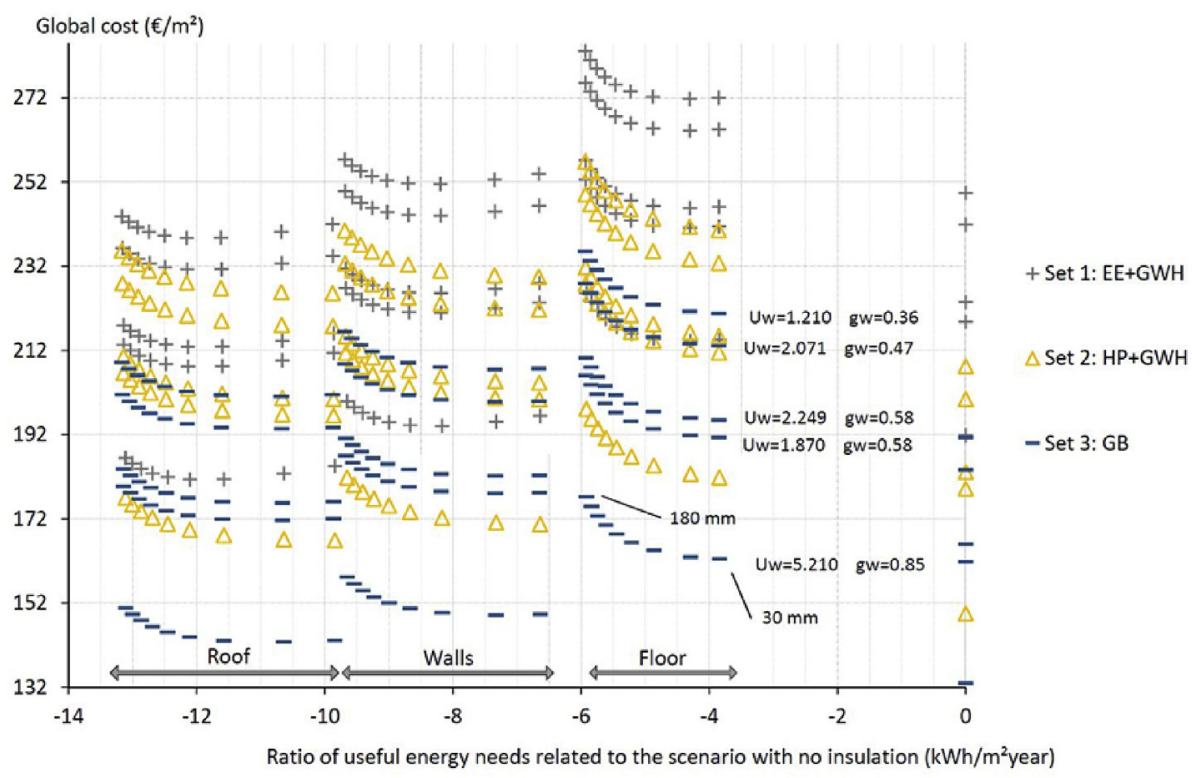

Fig. 13. Global cost for the different thickness of insulation, windows and energy systems. For each window, the heat transfer coefficient $\mathrm{U}_{\mathrm{w}}\left(\mathrm{W} / \mathrm{m}^{2} \mathrm{~K}\right)$ and solar factor $\mathrm{g}_{\mathrm{w}}$ are shown. The thicknesses considered are $30,40,60,80,100,120,140,160$ and $180 \mathrm{~mm}$. The relative position of these two variables is the same for the other insulation types and energy systems. 
The comparison of these different types of insulation showed that the investment in roof insulation proved more effective than investment in exterior walls or floor, from both the economic and the energy-efficient point of view. Once it has been decided to invest in insulation, the best thickness options for the roof, exterior walls and floor will always be associated with the CG system and the window with $U_{w}=5.10 \mathrm{~W} / \mathrm{m}^{2} \mathrm{~K}$. Thanks to its higher energy need, EE is the only system for which the global cost can be reduced by adding insulation. Again, the optimal energy systems (GB and HP) can be easily identified and then the same can be done for the type of element insulated and its thickness, and the windows. This procedure leads to the package of measures obtained by 'brute force' in the previous section.

\section{Conclusions}

In this paper, an expeditious procedure to identify the optimal energy systems of residential buildings has been proposed in terms of both primary energy consumption and global cost. This method can be implemented easily and allows technicians to quickly compare the energy solutions from the user's point of view.

Furthermore, looking for the cost-optimal package of renovation measures has shown the dominance of energy systems. Taking this into account, the cost-optimal package could be estimated by adding the cost-optimal insulation measures to the cost-optimal energy system configuration identified by the simplified method. Proceeding in this way, the complexity of a 'full-scale' cost-optimal problem is avoided. A great effort has been made to deal with the complexity involved in the search among a large number of combinations of measures. However, the simplified calculations described in the present work make it possible to pinpoint the most convenient energy measures in the detached dwellings that are very common in the Portuguese housing stock. Refurbishment works are needed by $38.1 \%$ of Portuguese houses to solve indoor thermal and hygrometric problems. This methodology has provided the same result as the official cost-optimal method established by EU regulations.

Although this expeditious procedure has been applied in this work to a representative dwelling of the Portuguese housing stock, it is equally applicable to different types of buildings, including non-residential buildings and buildings in other climatic regions. It is also possible to aggregate energy needs for cooling, which was not considered in this work.

There is a great divergence in Portuguese houses between nominal energy needs and actual energy consumption. In conclusion, when the energy systems of a dwelling are subject to renewal, the cost-optimal calculation according to the building code in force can lead to choosing a wrong option: the cost-optimal energy system could require a high investment and might provide lower than expected energy savings.

It is important to emphasize that policymakers must consider real energy needs so that the building owner can make an investment analysis that is closer to actual energy consumption patterns. Only if solution providers and other stakeholders make use of practical and simple methods will the effective investment in measures of energy efficiency in buildings be fostered.

\section{Conflicts of interest}

The authors declare that they have no conflict of interest.

\section{Acknowledgements}

Sérgio Tadeu is grateful for the financial support provided by the Fundação de Amparo à Pesquisa do Estado de São Paulo through grant PIPE - 2016/00880-9 (Brazil). Márcio Gonçalves is grateful for the support by the doctoral FCT grant PD/BD/135194/2017. Guillermo Bastos Costas wishes to acknowledge the support from the University of Vigo through a grant that covered a three-month research stay abroad.
This work was framed within the project Expert A+ (POCI-01-0246FEDER-026751) funded by Portugal 2020 through the COMPETE 2020 programme.

\section{Appendix A. Supplementary data}

Supplementary data to this article can be found online at https:// doi.org/10.1016/j.jobe.2019.100838.

\section{References}

[1] A. Allouhi, Y. Fouih, T. Kousksou, A. Jamil, Y. Zeraouli, Y. Mourad, Energy consumption and efficiency in buildings: current status and future trends, J. Clean. Prod. 109 (2015) 118-130.

[2] European Commission, Directive 2010/31/EU of the European parliament and of council of 19 May 2010 on the energy performance of buildings (recast), Off. J. Eur. Union (2010) 13-35.

[3] European Commission, Directive (EU) 2018/844 of the European Parliament and of the Council of 30 May 2018 amending Directive 2010/31/EU on the energy performance of buildings and Directive 2012/27/EU on energy efficiency, Off. J. Eur. Union (2018) 75-91.

[4] European Commission, Policy Report, Roadmap 2050: A Practical Guide to Prosperous Low-Carbon Europe vol. 2, (2010).

[5] European Commission, Commission Delegated Regulation (EU) No 244/2012 of 16 January 2012 supplementing Directive 2010/31/EU of the European Parliament and of the Council on the energy performance of buildings by establishing a comparative methodology framework for calculating, Off. J. Eur. Union (2012) L 81/ 18-36.

[6] European Commission, Guidelines accompanying Commission Delegated Regulation (EU) No 244/2012 of 16 January 2012 supplementing Directive 2010/ 31/EU of the European Parliament and of the Council on the energy performance of buildings by establishing a comparative methodology framework for calculating cost-optimal levels of minimum energy performance requirements for buildings and building elements, Off. J. Eur. Union (2012) 1-28.

[7] EN 15459 - Energy Performance of Buildings - Economic Evaluation Procedure for Energy Systems in Buildings, European Committee of Standardisation, Bruxels, 2007.

[8] Buildings Performance Institute Europe (BPIE), Implementing the Cost-Optimal Methodology in EU Countries. Lessons Learned from Three Case Studies, (2013).

[9] C. Araújo, M. Almeida, L. Bragança, J.A. Barbosa, Cost-benefit analysis method for building solutions, Appl. Energy 173 (2016) 124-133.

[10] C. Becchio, S.P. Corgnati, L. Orlietti, G. Spigliantini, Proposal for a modified costoptimal approach by introducing benefits evaluation, Energy Procedia 82 (2015) 445-451.

[11] L. Boeck, S. Verbeke, A. Audenaert, L. Mesmaeker, Improving the energy performance of residential buildings: a literature review, Renew. Sustain. Energy Rev. 52 (2015) 960-975.

[12] M. Hamdy, A.-T. Nguyen, J.L.M. Hensen, A performance comparison of multi-objective optimization algorithms for solving nearly-zero-energy-building design problems, Energy Build. 121 (2016) 57-71.

[13] W. Tian, A review of sensitivity analysis methods in building energy analysis, Renew. Sustain. Energy Rev. 20 (2013) 411-419.

[14] R. Evins, A review of computational optimisation methods applied to sustainable building design, Renew. Sustain. Energy Rev. 22 (2013) 230-245.

[15] S. Tadeu, R.F. Alexandre, A. Tadeu, C. Henggeler Antunes, N. Simões, P. Pereira da Silva, A comparison between cost optimality and return on investment for energy retrofit in buildings - a real options perspective, Sustain. Cities Soc. 21 (2016) $12-25$.

[16] F. Ascione, N. Bianco, C. Stasio, G.M. Mauro, G.P. Vanoli, CASA, cost-optimal analysis by multi-objective optimisation and artificial neural networks: a new framework for the robust assessment of cost-optimal energy retrofit, feasible for any building, Energy Build. 146 (2017) 200-219 2017.

[17] R. Ruparathna, K. Hewage, R. Sadiq, Economic evaluation of building energy retrofits: a fuzzy based approach, Energy Build. 139 (2017) 395-406.

[18] M.M. Eskander, M. Sandoval-Reyes, C.A. Silva, S.M. Vieira, J.M.C. Sousa, Assessment of energy efficiency measures using multi-objective optimization in Portuguese households, Sustain. Cities Soc. 35 (2017) 764-773.

[19] F.G. Üçtuğ, E. Yükseltan, A linear programming approach to household energy conservation: efficient allocation of budget, Energy Build. 49 (2012) 200-208.

[20] J. Lizana, Y. Barrios-Padura, M. Molina-Huelva, R. Chacartegui, Multi-criteria assessment for the effective decision management in residential energy retrofitting, Energy Build. 129 (2016) 284-307.

[21] Seyda Emekci, A Life Cycle Costing Based Decision Support Tool for Cost-Optimal Energy Efficient Design And/or Refurbishments, Doctor of Philosophy Thesis School of Natural and Applied Sciences of Middle East Technical University, 2018.

[22] ECOFYS, Optimising the Energy Use of Technical Building Systems - Unleashing the Power of the EPBD's Article 8, (2017).

[23] J. Ferreira, M. Duarte Pinheiro, J. Brito, Refurbishment decision support tools: a review from a Portuguese user's perspective, Constr. Build. Mater. 49 (2013) 425-447.

[24] I.Z. Bribián, A.A. Usón, S. Scarpellini, Life cycle assessment in buildings: State-ofthe-art and simplified LCA, Build. Environ. 44 (2009) 2510-2520. 
[25] S. Tadeu, A. Tadeu, N. Simões, M. Gonçalves, The impact of thermal insulation cost on the profitability of energy rehabilitation of buildings, 40th IAHS World Congress on Housing, Madeira, Portugal, 2014, pp. 1-10.

[26] E. Di Giuseppe, M. Iannaccone, M. Telloni, M. D'Orazio, C. Di Perna, Probabilistic life cycle costing of existing buildings retrofit interventions towards NZEB target: methodology and application example, Energy Build. 144 (2017) 416-432.

[27] Decree-Law No. 28/2016, Diário da República, 2016, pp. 3-4.

[28] Instituto Nacional de Estatística (INE) and DGEG, Inquérito ao Consumo de Energia no Sector Doméstico 2010, (2010).

[29] INE/PORDATA, Buildings, According to the Census: Total and by Construction Date, (2015).

[30] L. Bragança, C. Wetzel, V. Buhagiar, L.G.W. Verhoef, Research in Architectural Engineering Series. Vol. 5 - COST C16 Improving the Quality of Existing Urban Building Envelopes - Facades and Roofs, IOS Press, Amsterdam, The Netherlands, 2007.

[31] Agência para a Energia (ADENE) - Sistema Certificação Energética dos Edifícios, SCE), 2017.

[32] C. Serra, N. Simões, S. Tadeu, A. Tadeu, Definition of Reference Buildings for Energy Performance Calculation - Portuguese Case, Energy for Sustainability, (2013) (Coimbra, Portugal).

[33] Ministério do Ambiente, Ordenamento do Território e Energia. Despacho n. ${ }^{\circ} 15793-$ E/2013, Diário da República 14 (2013) 14-25.

[34] S. Tadeu, N. Simões, M. Gonçalves, J. Ribeiro, Energy efficiency measures in Portuguese residential buildings constructed before 1960: a cost-optimal assessment, Energy for Sustainability 2013 - Sustainable Cities, Designing for People and the Planet, 2013.

[35] S. Tadeu, C. Rodrigues, A. Tadeu, F. Freire, N. Simões, Energy retrofit of an historic building in a UNESCO world heritage site: an integrated cost optimality and environmental assessment, International Conference in Energy Efficiency in Historic Buildings, 2014 Madrid, Spain.

[36] S. Tadeu, A. Tadeu, N. Simões, M. Gonçalves, R. Prado, A Sensitivity Analysis of a Cost Optimality Study on the Energy Retrofit of a Single-Family Reference Building in Portugal, Energy Efficiency, 2018.

[37] International Energy Agency (IEA) and United Nations Development Programme (UNDP), Policy Pathways: Modernising Building Energy Codes, (2013).

[38] M. Almeida, A. Rodrigues, M. Ferreira, Cost optimality and nZEB target in the renovation of Portuguese building stock - rainha Dina Leonor neighbourhood case study, Sustain. Build. Conf. SB13 Proc. (2013) 35-42.

[39] S. Wei, R. Jones, P. Wilde, Driving factors for occupant-controlled space heating in residential buildings, Energy Build. 70 (2014) 36-44.

[40] C.A. Balaras, A.G. Gaglia, E. Georgopoulou, S. Mirasgedis, Y. Sarafidis, D.P. Lalas, European residential buildings and empirical assessment of the Hellenic building stock, energy consumption, emissions and potential energy savings, Build. Environ. 42 (3) (2007) 1298-1314.

[41] R. Sunikka-Blank, M. Galvin, Introducing the pre-bound effect: the gap between performance and actual energy consumption, Build. Res. Inf. (2012).

[42] S.M.C. Magalhães, V.M.S. Leal, Characterization of thermal performance and nominal heating gap of the residential building stock using the EPBD-derived databases: the case of Portugal mainland, Energy Build. 70 (2014) 167-179.

[43] ISO EN 13790 - Energy Performance of Buildings - Calculations of Energy Use for Space Heating and Cooling, (2008).

[44] ADENE, Portal SCE - Sistema Certificação Energética Dos Edifícios, (2014) accessed in 2014 www.adene.pt/sce.

[45] "Diário da República, nº 15793-I/20013 (extrato), 2. a série - N. ${ }^{\circ} 234-3$ de dezembro de 2013, (2013).

[46] Comissão Europeia, EU energy, transport and GHG emissions: trends to 2050, Reference Scenario (2013) 2013.

[47] Energy Services Regulatory Authority, Reference Prices in the Liberalized Market of Electricity and Natural Gas in Continental Portugal, (2017) (in Portuguese).

[48] Caixa geral de Depósitos, credit for rehabilitation, accessed in, 2017. https://www. cgd.pt/Particulares/Credito/Habitacao/Pages/Credito-habitacao-Regime-Geral. aspx.

[49] S. A. CYPE Ingenieros, Gerador de preços para construção civil, v, (2013) (in Portuguese).

\section{Nomenclature}

\section{Abbreviations}

$B B$ : Biomass boiler

$D G E G$ : General Directorate for Energy and Geology

$D H W$ : Domestic hot water

ECS: Energy Certification System

EE: Electric heater

$E U$ : European Union

EPBD: Energy Performance in Buildings Directive

$G B$ : Gas boiler

$G W H:$ Gas water heater

$H D D$ : Heating degree days $\left[{ }^{\circ} \mathrm{C}\right.$. day $]$

$H P$ : Heat pump

ICESD: Survey on Energy Consumption in the Domestic Sector

INE: National Statistics Institute

$P E$ : Primary energy

MS: Member State

VAT: Value-added tax

\section{Symbols}

$h_{m}$ : Height of ceilings [m]

$C_{e n, w, k, i}:$ Energy price $[€ / \mathrm{kWh}]$

$C_{j, i}:$ Annual costs $[€]$

$D_{\tau}$ : Discount factor

$E_{h, k}$ : Heating energy needs $\left[\mathrm{kWh} /\left(\mathrm{m}^{2}\right.\right.$.year $\left.)\right]$

$E C_{w, k, i}$ : Energy cost in the year i [€]

$E_{w, k}$ : Domestic hot water energy production $\left[\mathrm{kWh} /\left(\mathrm{m}^{2} . \mathrm{year}\right)\right]$

$F E_{w, k}$ : Final energy needs $\left[\mathrm{kWh} /\left(\mathrm{m}^{2}\right.\right.$. year $\left.)\right]$

$G C_{w, k}$ : Global costs [€]

$I_{j}:$ Initial investment costs $[€]$

$M_{w, k, i}:$ Maintenance cost in the year I [€]

$P_{k j}$ : Conversion factor between final energy and primary energy

$Q_{\text {gain }}$ : Heat gains [kWh/year]

$Q_{t r, i}$ : Heat transfer coefficient by transmission [kWh/year]

$Q_{v e, i}:$ Heat transfer coefficient by ventilation $[\mathrm{kWh} /$ year]

$V_{\tau, j}$ : Residual value associated with each measure $[€]$

$f_{h, k}$ : Percentage of the energy needs for space heating [\%]

$f_{w, k}$ : Percentage of the energy needs DHW [\%]

$A:$ Area $\left[\mathrm{m}^{2}\right]$

$\mathrm{CO}_{2}$ : Carbon dioxide

$g_{w}$ : Solar factor of the glazing

$U$ : Thermal transmittance $\left[\mathrm{W} /\left(\mathrm{m}^{2} .{ }^{\circ} \mathrm{C}\right)\right]$

$E$ : Useful energy needs $\left[\mathrm{kWh} /\left(\mathrm{m}^{2}\right.\right.$.year $\left.)\right]$

$G(\tau)$ : Global cost $[€]$

$K$ : Number of systems

$M$ : Average daily DHW consumption [litres/year]

$N M$ : Number of measures

$r$ : Real discount rate [\%]

$\eta$ : Efficiency

$\tau$ : Calculation period [years] 